\title{
Tobacco control policies in relation to child health and perinatal health outcomes
}

\author{
Jasper V Been, 1,2,3 Aziz Sheikh ${ }^{3,4}$
}

\begin{abstract}
BURDEN OF TOBACCO-RELATED HARM
The global epidemic of tobacco use continues to cause a considerable burden of premature death and disease. ${ }^{12}$ Worldwide, over 1 billion people are regular smokers, and the societal costs of smoking have been estimated at over $£ 1$ trillion/ year. ${ }^{13}$ Tobacco is relevant to child health in various ways. Unborn children may be exposed to tobacco when their mothers smoke, are exposed to secondhand smoke (SHS) or use smokeless tobacco products. Antenatal tobacco smoke exposure can lead to birth defects, preterm birth, intrauterine growth restriction and stillbirth. ${ }^{4-6}$ After birth, exposure to SHS increases the risks of neonatal and infant death, otitis media with effusion, respiratory tract infections (RTIs), meningococcal disease and asthma attacks. ${ }^{56}$ Furthermore, earlylife tobacco smoke exposure increases the likelihood that the child will become a smoker later in life. In this paper, we discuss how tobacco control measures may improve early life health outcomes and highlight key knowledge gaps.
\end{abstract}

\section{CONTROLLING THE TOBACCO EPIDEMIC}

Based on international treaties, in particular, the Convention of the Rights of the Child, there is consensus that every child should have the right to grow up free from the adverse health effects of tobacco. ${ }^{7}$ Children, particularly when young, are entirely dependent on decisions made by adults in relation to tobacco and SHS exposure. Tobacco control policies can help guide these decisions, for example, by informing the public about the dangers

'Division of Neonatology, Department of Paediatrics, Erasmus MC - Sophia Children's Hospital, Rotterdam, The Netherlands

${ }^{2}$ Department of Obstetrics and Gynaecology, Erasmus MC - Sophia Children's Hospital, Rotterdam, The Netherlands

${ }^{3}$ Usher Institute of Population Health Sciences and Informatics, The University of Edinburgh, Edinburgh, UK ${ }^{4}$ Division of General Internal Medicine and Primary Care, Brigham and Women's Hospital/Harvard Medical School, Boston, Massachusetts, USA

Correspondence to Dr Jasper $\vee$ Been, Division of Neonatology, Department of Paediatrics, Erasmus MC - Sophia Children's Hospital, 3000CB Rotterdam, The Netherlands; j.been@erasmusmc.nl of tobacco use and SHS exposure, prohibiting smoking in public places and in cars and reducing parental smoking through decreasing the attractiveness of tobacco products via price increases and marketing restrictions. To facilitate governments in applying what has been set out in the widely endorsed international Framework Convention for Tobacco Control (FCTC) treaty, the WHO has formulated six key (groups of) tobacco control policies that participating countries need to implement, represented by the MPOWER acronym (box 1). ${ }^{1}$ Ample evidence now supports the considerable impact of such policies on reducing tobacco use and improving population health, ${ }^{8}{ }^{9}$ including that of children.

\section{IMPACT OF TOBACCO CONTROL ON CHILD HEALTH}

\section{Smoke-free legislation}

A recent systematic review identified 35 well-designed studies from North America, Europe and China assessing the impact of smoke-free legislation on child health. ${ }^{10}$ Meta-analyses indicated that implementation of smoke-free policies was associated with sizeable reductions in adverse early-life health outcomes, including preterm birth $(-3.8 \%, 95 \% \mathrm{CI}-6.4 \%$ to $-1.2 \%)$, severe asthma attacks $(-9.8 \%, 95 \% \mathrm{CI}-16.6 \%$ to $-3.0 \%)$ and severe lower RTIs $(-18.5 \%$, $95 \%$ CI $-32.8 \%$ to $-4.2 \%) .{ }^{10}$ These effects are important given that preterm birth and RTIs are the primary contributors to the

Box 1 MPOWER tobacco control measures advocated by the WHO

- M: monitor tobacco use and prevention policies

- P: protect people from tobacco smoke (eg, smoke-free legislation)

- 0: offer help to quit tobacco use

- W: warn about the dangers of tobacco

- E: enforce bans on tobacco advertising, promotion and sponsorship

- R: raise taxes on tobacco. global burden of adverse child health. ${ }^{11}$ In line with evidence from studies in adults, ${ }^{12}$ smoke-free laws had the largest benefit when comprehensively applied (ie, covering a wide range of public places). ${ }^{10}$ Smoke-free legislation appears to exert its effect through reducing SHS exposure among children and pregnant women, reducing parental smoking prevalence and changing social norms, for example, resulting in many people making their homes smoke free. ${ }^{56}$ Furthermore, recent evidence from the UK indicates that implementation of smoke-free legislation may help reduce smoking initiation at school age. ${ }^{13}$

\section{Taxation and other policies}

Tobacco taxation is the most effective tool to reduce smoking prevalence, ${ }^{1}$ and through doing so it has been shown to benefit perinatal and child health. ${ }^{10}$ For example, consistent reductions in infant mortality were demonstrated following tobacco tax/price increases in the USA, Canada and the European Union. ${ }^{14-16}$ Improvements in child health have also been demonstrated after implementation of other tobacco control policies in the USA $^{10}$ : governmental provision of smoking cessation services has been associated with a reduction in severe RTIs, ${ }^{17}$ and there was a reduction in low birthweight babies following an increase in the legal age for cigarette purchasing. ${ }^{18}$

\section{KNOWLEDGE GAPS}

\section{Impact of novel policies}

Now that MPOWER's impact is well established, ${ }^{8-10}$ there is a need to formally assess the effectiveness of newer tobacco control efforts in promoting population health, including that of children. This includes legislation to reduce SHS exposure in outdoor public places frequented by children, such as playgrounds, school grounds and parks, and also in enclosed private spaces such as cars. Smoking in cars results in very high exposure to harmful tobacco combustion products, and prohibiting smoking in private-in addition to public-vehicles can effectively reduce children's SHS exposure. ${ }^{19} 20$ Adolescents may in addition benefit from policies to reduce the attractiveness of smoking, such as banning the display of tobacco products in shops and introducing plain packaging. In New Zealand, the display ban was followed by a reduction in smoking experimentation and initiation among youth. ${ }^{21}$ Introduction of plain packaging in Australia was followed by a stronger-than-anticipated response 
among adolescents in terms of initiation and quitting behaviour. ${ }^{22}$ Additional studies in other countries where similar policies were recently implemented, such as the UK, are needed to support these initial observations. Impact assessment is furthermore needed of policies prohibiting flavoured tobacco products; such products are particularly appealing to youth, who wrongfully tend to perceive them as being less harmful than non-flavoured products. ${ }^{23}$

\section{Tobacco control in low-and middle- income countries (LMICs)}

A particularly pressing issue is the lack of studies assessing the child health impact of tobacco control policies in LMICs. ${ }^{10}$ Tobacco companies are increasingly targeting LMICs, which are already experiencing the largest burden of tobacco-related premature mortality and morbidity. ${ }^{2}$ Studies assessing the effectiveness of tobacco control policies in LMICs are therefore urgently needed. Partnerships between institutions from high-income countries and LMIC partners, supported by initiatives such as the Global Challenges Research Fund, offer the opportunity to address this knowledge gap.

\section{Thirdhand smoke (THS)}

The potential effects of THS are likely to have been underestimated so far. THS are tobacco smoke constituents that remain on surfaces that have been exposed, such as clothes, hair and skin, and also curtains, walls and floors. Children may experience potential harm from THS via inhalation, dermal absorption or ingestion. Its lingering nature was highlighted in a recent study demonstrating relevant THS exposure in a significant proportion of non-smokers up to 2 months after moving into a house previously owned by smokers. ${ }^{24}$ Environmental THS pollution is present in homes of families with young infants ${ }^{25}$ and even in a neonatal intensive care environment, including on incubators and parents' hands despite handwashing. ${ }^{26}$ Smoking outside is ineffective in preventing THS exposure in the home $\mathrm{e}^{25}$ or in normalising the risk of respiratory symptoms among children. ${ }^{27}$ Research is needed to further assess the potential harms associated with childhood THS exposure, as well as to assess the effectiveness of efforts to eliminate exposure. ${ }^{6}$

\section{e-Cigarettes}

Electronic nicotine delivery systems (ENDS) are upcoming on the tobacco market and are causing much debate.
While they may confer benefit as a harm reduction approach among established smokers, evidence from the USA suggests that ENDS can be a gateway to smoking among youth. ${ }^{28}$ ENDS have caused harm via explosion on a number of occasions, and unintentional ingestion of nicotine refill liquids can cause serious harm among toddlers. Although ENDS avoid inhalation of harmful combustion products, research has raised concerns over their impact on health. ${ }^{28}$ More research is needed, including on the potential health impact of secondhand aerosol exposure and of using ENDS during pregnancy. Meanwhile, it is prudent to regulate ENDS in similar ways as combustibles and restrict their promotion to youth. Comprehensive reports on ENDS are available for background reading. ${ }^{28} 29$

\section{IMPLICATIONS FOR POLICY AND PRACTICE \\ Translating evidence into policy}

Considering the large evidence base supporting the effectiveness of tobacco control in reducing smoking prevalence, SHS exposure and related harms and the ratification of the FCTC by 181 countries, it is of significant concern that MPOWER policies are only fully implemented by a minority of countries. ${ }^{1}$ To accelerate the global adoption of effective tobacco control measures, it is essential that research findings are successfully communicated to policymakers. Researchers in the field should be aware of their responsibility in this regard and seek opportunities to engage with policymakers and the media so as to help shape evidence-based policy in the future. ${ }^{30}$ Additionally, advocacy by health professionals has helped accelerate implementation of smoke-free public places as well as smoke-free cars in the UK, ${ }^{31}$ providing an example for other countries where such policies are currently lacking.

\section{Tackling tobacco industry involvement}

It is important to be aware of the tobacco industry's role in frustrating the policy process towards effective tobacco control as well as their tactics to reduce the effectiveness of such policies. As an example, evidence from the UK indicates that the industry responds to tobacco tax increases by lowering the price of the cheapest cigarette brands, allowing smokers to switch to budget cigarettes and through doing so sustain their addiction. ${ }^{32}$ A recent study across 23 European Union countries found that this approach is associated with increased infant mortality, ${ }^{16}$ highlighting the public health relevance of recognising and addressing such tactics.

\section{Tobacco endgame}

In recent years, policy development has progressed from thinking about how to control the impact of the tobacco epidemic towards pursuing a tobacco-free society within a specific timeframe. ${ }^{33}$ An excellent overview of promising policies that fit this 'tobacco endgame' concept was recently provided by McDaniel and colleagues. ${ }^{33}$ Examples include reducing the nicotine content of tobacco products to make them less addictive and prohibiting features designed to mask the harshness of tobacco smoke inhalation, such as additives and filters. Cigarette use may be regulated via issuing smokers' licences with age restrictions and purchase limits or via provision of cigarettes on prescription, provided only after prior cessation attempts have failed. Other approaches include restricting the number of outlets or licences to sell tobacco products and introducing quota on cigarette production and import. Additional and potentially more forward-thinking policies are likely to be developed in the near future, and there is a need to assess their potential to benefit population health, including that of children.

\section{CONCLUSION}

Children benefit substantially from policies to reduce smoking and SHS exposure. Governments should accelerate the global uptake of such policies while the effectiveness of novel approaches is scientifically assessed so that protection from tobacco-related harm is further optimised for some of the most vulnerable members of society.

Contributors JVB drafted the manuscript; AS supervised the writing.

Funding JVB is funded by personal fellowships from the Netherlands Lung Foundation (4.2.14.063J0) and the Erasmus MC. AS is supported by the Farr Institute and the Asthma UK Centre for Applied Research.

Competing interests None declared.

Provenance and peer review Commissioned; externally peer reviewed.

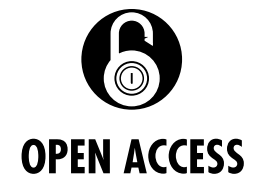

Open access This is an open access article distributed in accordance with the Creative Commons Attribution Non Commercial (CC BY-NC 4.0) license, which permits others to distribute, remix, adapt, build upon this work non-commercially, and license their derivative works on different terms, provided the original work is properly 
cited and the use is non-commercial. See: http:// creativecommons.org/licenses/by-nc/4.0/

(c) Article author(s) (or their employer(s) unless otherwise stated in the text of the article) 2018. All rights reserved. No commercial use is permitted unless otherwise expressly granted.

\section{A) Check for updates}

To cite Been JV, Sheikh A. Arch Dis Child 2018;103:817-819.

Received 18 November 2017

Revised 26 January 2018

Accepted 31 January 2018

Published Online First 3 April 2018

Arch Dis Child 2018:103:817-819.

doi:10.1136/archdischild-2017-313680

\section{REFERENCES}

1 World Health Organization. WHO report on the global tobacco epidemic, 2017. Monitoring tobacco use and prevention policies. $2017 \mathrm{http}: / / \mathrm{ww}$ w. who.int/tobacco/ global_report/2017/en (accessed 18 Nov 2017).

2 GBD 2015 Tobacco Collaborators. Smoking prevalence and attributable disease burden in 195 countries and territories, 1990-2015: a systematic analysis from the Global Burden of Disease Study 2015. Lancet 2017;389:1885-906

3 National Cancer Institute, World Health Organization. The economics of tobacco and tobacco control: $\mathrm{NCl}$ Tobacco control monograph series, 2017.

4 Wagijo MA, Sheikh A, Duijts L, et al. Reducing tobacco smoking and smoke exposure to prevent preterm birth and its complications. Paediatr Respir Rev 2017:22:3-10.

5 Faber T, Been JV, Reiss IK, et al. Smoke-free legislation and child health. NPJ Prim Care Respir Med 2016;26:16067

6 Pugmire J, Sweeting H, Moore L. Environmental tobacco smoke exposure among infants, children and young people: now is no time to relax. Arch Dis Child 2017; 102:117-8.

7 Toebes B, Gispen ME, Been JV, et al. A missing voice: the human rights of children to a tobacco-free environment. Tob Control 2018;27:3-5.

8 Gravely S, Giovino GA, Craig L, et al. Implementation of key demand-reduction measures of the WHO Framework Convention on Tobacco Control and change in smoking prevalence in 126 countries: an association study. Lancet Public Health 2017;2:e166-74.

9 Hoffman SJ, Tan C. Overview of systematic reviews on the health-related effects of government tobacco control policies. BMC Public Health 2015;15:744.

10 Faber T, Kumar A, Mackenbach JP, et al. Effect of tobacco control policies on perinatal and child health: a systematic review and meta-analysis. Lancet Public Health 2017:2:e420-37.

$11 \mathrm{Kyu} \mathrm{HH}$, Pinho C, Wagner JA, et al. Global and national burden of diseases and injuries among children and adolescents between 1990 and 2013: findings from the Global Burden of Disease 2013 Study. JAMA Pediatr 2016;170:267-87.

12 Tan CE, Glantz SA. Association between smokefree legislation and hospitalizations for cardiac, cerebrovascular, and respiratory diseases: a metaanalysis. Circulation 2012:126:2177-83.

13 Katikireddi SV, Der G, Roberts C, et al. Has childhood smoking reduced following smoke-free public places legislation? A segmented regression analysis of crosssectional UK school-based surveys. Nicotine Tob Res 2016:18:1670-4.

14 Patrick SW, Warner KE, Pordes E, et al. Cigarette tax increase and infant mortality. Pediatrics 2016;137:e20152901.

15 Sen A, Piérard E. Estimating the effects of cigarette taxes on birth outcomes. Can Public Policy 2011:37:257-76

16 Filippidis FT, Laverty AA, Hone T, et al. Association of cigarette price differentials with infant mortality in 23 European Union countries. JAMA Pediat 2017:171:1100-6

17 Hawkins SS, Hristakeva S, Gottlieb M, et al. Reduction in emergency department visits for children's asthma, ear infections, and respiratory infections after the introduction of state smoke-free legislation. Prev Med 2016:89:278-85.

18 Yan J. The effects of a minimum cigarette purchase age of 21 on prenatal smoking and infant health. East Econ J 2014:40:289-308.

19 Elton-Marshall T, Leatherdale ST, Driezen P, et al. Do provincial policies banning smoking in cars when children are present impact youth exposure to secondhand smoke in cars? Prev Med 2015;78:59-64.

20 Nguyen HV. Do smoke-free car laws work? Evidence from a quasi-experiment. J Health Econ 2013;32:138-48.

21 Edwards R, Ajmal A, Healey B, et al. Impact of removing point-of-sale tobacco displays: data from a New Zealand youth survey. Tob Control 2017:26:392-8.

22 Dunlop S, Perez D, Dessaix A, et al. Australia's plain tobacco packs: anticipated and actual responses among adolescents and young adults 2010-2013. Tob Control 2016

23 Huang LL, Baker HM, Meernik C, et al. Impact of nonmenthol flavours in tobacco products on perceptions and use among youth, young adults and adults: a systematic review. Tob Control 2017:26:709-19.

24 Matt GE, Quintana PJ, Zakarian JM, et al. When smokers move out and non-smokers move in: residential thirdhand smoke pollution and exposure. Tob Control 2011;20:e1

25 Northrup TF, Matt GE, Hovell MF, et al. Thirdhand smoke in the homes of medically fragile children: assessing the impact of indoor smoking levels and smoking bans. Nicotine Tob Res 2016;18:1290-8.

26 Northrup TF, Khan AM, Jacob P, et al. Thirdhand smoke contamination in hospital settings: assessing exposure risk for vulnerable paediatric patients. Tob Control 2016;25:619-23

27 Leung LT, Ho SY, Wang MP, et al. Secondhand smoke from multiple sources, thirdhand smoke and respiratory symptoms in Hong Kong adolescents. Nicotine Tob Res 2018:20:192-8

28 National Academies of Sciences Engineering Medicine. Public health consequences of e-cigarettes. 2018 https://www.nap.edu/catalog/24952/public-healthconsequences-of-e-cigarettes (accessed 26 Jan 2018).

29 McNeill A, Brose A, Calder A, et al. Evidence review of ecigarettes and heated tobacco products 2018. A report commissioned by Public Health England. London: Public Health England, 2018. https:// www.gov.uk/government/uploads/system/uploads/ attachment_data/file/680964/Evidence_review_of e-cigarettes_and_heated_tobacco_products_2018. pdf

30 Lemer C, Cheung CR, Viner R, et al. Health policy research: successes and challenges. Arch Dis Child 2015;100:376-9.

31 Hopkinson NS, Majeed A, Britton J, et al. Respiratory health professionals call on MPs to vote to ban smoking in cars with children. BMJ 2014;348:g1395

32 Gilmore AB, Tavakoly B, Taylor G, et al. Understanding tobacco industry pricing strategy and whether it undermines tobacco tax policy: the example of the UK cigarette market. Addiction 2013:108:1317-26.

33 McDaniel PA, Smith EA, Malone RE. The tobacco endgame: a qualitative review and synthesis. Tob Control 2016:25:594-604. 